\title{
Assessing Children's Computational Skills: Validation of an Adapted Version of the Canadian Achievement Test - Second Edition for 10 year olds.
}

\author{
Garon-Carrier, G. ${ }^{1}$, Boivin, M. ${ }^{1,2}$, Ouellet, E. ${ }^{3}$, Tremblay, R. E. ${ }^{2,4,5}$, \& Dionne, G. ${ }^{1}$ \\ ${ }^{1}$ School of Psychology, Université Laval, Canada \\ ${ }^{2}$ Institute of Genetic, Neurobiological, and Social Foundations of Child Development, Tomsk \\ State University, Tomsk, Russian Federation \\ ${ }^{3} \mathrm{CHU}$ de Québec Research Center, Canada \\ ${ }^{4}$ Department of Pediatrics and Psychology, Université de Montréal, Canada \\ ${ }^{5}$ School of Public Health, Physiotherapy and Population Sciences, University College Dublin, \\ Ireland
}

Correspondence concerning this article should be sent to Ginette Dionne, Professor, École de psychologie, Université Laval, Québec, Canada, G1K 7P4.

Email: Ginette.Dionne@psy.ulaval.ca 


\begin{abstract}
This study tested the validity of the mathematic subtest of the Canadian Achievement Test Second Edition (CAT/2; Canadian Test Centre, 1992) for 10 year olds, adapted from the original version administered at age 8 . The analyses showed satisfactory internal consistency of the adapted version at age 10 , and slightly higher internal consistency than that of the original version at age $8(.81$ vs .76). The total scores distribution of the age 10 version were slightly negatively skewed, suggesting that the tool is sensitive to assess children with lower mathematic abilities. Using a correlational design, the results showed substantial cross-age convergent validity between the age 8 and age 10 versions $(.49, \mathrm{p}<.001)$, and cross-measure convergent and discriminant validity of this adapted version. We conclude that the adapted mathematics subtest of the Canadian Achievement Test could be used to reliably measure children's computational skills at age 10 .
\end{abstract}

Keywords: Validation, Mathematics, School achievement, Teacher reports, Computational skills. 


\section{Assessing Children's Computational Skills: Validation of an Adapted Version of the Canadian Achievement Test - Second Edition for 10 year olds}

Frequent and ongoing assessment of mathematic abilities during childhood is paramount to ensure an optimal development of these skills. At the individual level, assessing mathematic abilities with standardized tools informs teachers and parents of a child's relative level of mastery and comprehension of mathematics, and may help identify delays that could be addressed by early interventions. At a population level, it provides useful benchmarks for mathematic programs adjustment and educational policy.

The Canadian achievement Test - second edition (CAT/2; Canadian Test Centre, 1992) measures general knowledge and performance in five content areas: reading, spelling, language, study skills and mathematics up to grade 3 . The present study focused on the mathematic content of the CAT/2. This age-appropriate test varies according to school grade. For example, at ages 8 and 9 (grades 2 and/or 3), the mathematic subscale of the CAT/2 consists of multiple-choice questions that assess children's capacity to compute addition, subtraction, and multiplication operations. This subtest was administered at age 8 (grade 2) in a Quebec sample of more than 1500 children.

Recently, we adapted the mathematic subtest of the CAT/2 to evaluate children's computational skills at age 10 . We first obtained the copyright permission of Canadian Test Centre to use the CAT/2 test items. We conducted a pilot study $(n=10)$ with kids of age 10 years. According to the teacher, these kids were classified into 3 levels: (1) low achievers (high difficulty); (2) moderate achievers (moderate difficulty); (3) high achievers (low difficulty). Items were created to reflect these 3 levels of difficulty. Based on the Quebec educational program curriculum in primary school, we increased the difficulty level of the addition, 
subtraction and multiplication operations by adding new items and eliminating items with little variance based on pilot testing. We also added division operations to the original test, as children are exposed to division operations for the first time around age 10 (MELS, 2013; NCTM, 2006). Items of the pilot testing that were $100 \%$ achieved and $0 \%$ achieved by children were removed. We kept $25 \%$ of the items achieved by less than $20 \%$ of children; $25 \%$ of items achieved by more than $80 \%$ of children; and $50 \%$ of items achieved by $20 \%$ to $80 \%$ of children.

The goal of the present study was to validate the adapted mathematic subtest of the CAT/2 for use with 10 year-olds by: 1) Assessing its' internal consistency and capacity to capture the variance in skills at age 10 (grade 4); 2) Assessing its' convergent validity with the original version at age 8; 3) Assessing its' convergent validity with standardized measures of mathematic and teacher reports of school achievement in various domains.

\section{Methods}

\section{Participants}

This report is based on an ongoing prospective longitudinal study of a representative sample of infants born in the province of Quebec, Canada in 1998. All infants of 59 and 60 weeks of gestational age were selected through the Master Birth Register of the Ministry of Health and Social Services. Those for whom the duration of the gestation could not be determined in the birth record, those born at less than 24 weeks or at more than 42 weeks of gestation or those living in the Far North administrative regions including Cree territory, Inuit territory, and aboriginal reserves were excluded. From 2675 families initially targeted, 2223 were

met for a first visit, and 2120 were followed on an annual basis from the age of 5 months (Jetté \& Des Groseillers, 2000). The CAT/2 was used to assess math skills at age 8 years on 1466 children, of whom 1147 in grade 2, 6 were in grade 1, and 18 in grade 3; and at age 10 years on 
1328 children, of whom 1165 were in grade 4, 19 in grade 1, 5 in grade 2, 39 in grade 3,29 in grade 5 , and 2 in grade 6 . The grade was not available for the remaining children.

\section{Instruments and Procedure}

Computational skills in mathematics. Computational skills were assessed at age 8 with the mathematic subtest of the Canadian Achievement Test - second edition (CAT/2; Canadian Test Center, 1992). This test assesses children's ability to perform additions, subtractions, and multiplications. Children had to choose the right answer out of four choices within a limited time for each item. One point was attributed for each correct answer. Scores were computed by adding the correct items, separately for each type of operation and for the whole test, with a maximum of 21 for the total test score. The internal consistency of this subtest in the Quebec sample was .76.

In the adapted version at age 10, twelve items from the original scale were retained based on their ability to capture variance in a small pilot sample. New items were developed for each operation to raise the difficulty level: 1 new item was developed for the addition, 1 item for subtraction and 2 items for multiplication. In addition, 4 division items were added to reflect the mathematics curriculum taught in grade 4 in the province of Quebec for a total of 20 items.

Number knowledge. Number knowledge was measured annually between the ages of 4 and 7 years with the standardized Number Knowledge Test (NKT; Okamoto \& Case, 1996). This test has 4 levels and follows the normative acquisition of number knowledge as a function of age (Gersten, Jordan, \& Flojo, 2005; Gersten Clarke, \& Jordan, 2007). An internal consistency of .94 was obtained from the item response reliability test (Gersten et al., 2007). Two different versions of the NKT were administered; an 18-item version administered at ages 4, 5 and 6, and a 27-item version at age 7. Strong associations between the computational skills and the number knowledge would indicate convergent validity for the adapted version of the CAT/2 mathematic subtest. 
Basic numeracy. The Early Development Instrument (EDI; Janus \& Offord, 2007) is a teacher-rated questionnaire that measures five broad domains of children's school readiness. Teachers completed this questionnaire when children were 6 years of age. We only used the items related to basic numeracy for the purpose of this study (11 items). Items were coded on a yes-no scale (1-0 score) reflecting whether the child has mastered the designated skill or not. The total numeracy score varies between 0 and 11 and the internal consistency for this subscale is .78. Strong associations between the basic numeracy module of the EDI and the score on the adapted version of the CAT/2 at age 10 would support convergent validity.

School achievement. School achievement was measured through teacher ratings of the child's achievement relative to his or her classmates at ages $7,8,10$ and 12 years $\left(1^{\text {st }}, 2^{\text {nd }}, 4^{\text {th }}\right.$ and $6^{\text {th }}$ grades). Teachers answered on a 5-point Likert scale from 1 (near the bottom of the class) to 5 (near the top of the class) to the following questions: "How would you rate this child's current academic achievement in mathematics?...reading?...written work?... science?” Teachers reported achievement in science only when children were 10 and 12 years of age. A higher association between the score on the adapted version of the CAT/2 at age 10 and teacher reports of mathematic achievement, compared to other school achievement domains, would support convergent and discriminant validity of the adapted tool.

\section{Analyses}

We analyzed missing data with the MVA module in SPSS 20.0 for Windows (SPSS Inc, Chicago, IL). Missing data for the CAT/2 at age 8 and the adapted version at age 10 were respectively $30.8 \%$ and $37.4 \% ; 54.5 \%$ for the basic numeracy module of the EDI (Janus \& Offord, 2007); between $16.6 \%$ and $53.3 \%$ for number knowledge from ages 4 to 7 ; and between $39.2 \%$ and $61.3 \%$ for school achievement from ages 7 to 12 . According to Little's MCAR test, 
data were missing completely at random for the school achievement measure $\left(\chi^{2}=1788.51, d f=\right.$ $1818, p>.05$, respectively), but were not missing completely at random for computational skills at 8 and $10\left(\chi^{2}=31.05, d f=10, p<.05\right)$, number knowledge $\left(\chi^{2}=57.90, d f=27, p<.05\right)$ and basic numeracy measures $\left(\chi^{2}=1317.88, d f=623, p<.05\right)$. A series of $t$-tests obtained with the MVA module showed that children who were missing on computational skills, number knowledge and basic numeracy tended to have lower mathematic skills and were from significantly lower socioeconomic background from ages 5 months to 5 years.

Therefore, we used the Full information maximum likelihood (FILM) method for the treatment of missing data, producing the least biased and most efficient parameter estimates (Peugh \& Enders, 2004; Graham, Olchowski, \& Gilreath, 2007). Correlations were calculated with children's age and school grade as control variables using Mplus 5.21 statistical package (Muthén \& Muthén, 1998-2004).

\section{Results}

Descriptive statistics for the computational skills at ages 8 and 10 are shown in Table 1 . Children performed more poorly in multiplication at age 8 , and in division at age 10 . Addition and subtraction are well mastered at both ages, while multiplication and division, as expected, are clearly more challenging. Descriptive statistics for number knowledge, basic numeracy, and achievement in mathematic, science, reading and writing are presented in Table 2. While number knowledge largely improved, academic achievement within each school domains slightly decreased over time. These results suggest that teachers tend to evaluate more positively children's academic achievement in early grades of primary school.

Figure 1 shows the data distribution for each operation subtest of the adapted mathematics scale of the CAT/2. The distributions were negatively skewed for addition $(-1.88)$ 
and subtraction (-1.97), but normally distributed for the multiplication and division. The total scores were also negatively skewed (-1.36), suggesting that this tool might be more discriminant for children in the lower curve of the distribution and thus, could potentially be used to detect children with lower mathematic abilities.

\section{Internal consistency}

An item response reliability test showed acceptable internal consistency for the adapted mathematic scale of the CAT/2 at age $10(\alpha=.81)$. Moreover, the internal consistency did not vary with the suppression of the items added or changed from the original test administered at age 8 .

\section{Cross-age convergent validity}

Correlations (see Table 3) supported the convergent validity between ages 8 and 10 computational skills measures with significant associations of .29 for addition, .34 for subtraction, .23 for multiplication and .47 for the total test score $(P s<.001)$. The division subscale at age 10 was also significantly associated with addition, subtraction, multiplication and the total score at age 8 , with correlations ranging from .21 and .35 . Correlations across operations at each age were comparable ranging from .30 to .60 .

\section{Cross-measure convergent validity}

The computational skills at ages 8 and 10 show similar associations with number knowledge, from ages 4 to 7 , albeit slightly stronger for the CAT/2 at age 8 . The correlations of number knowledge with the adapted age 10 subtests ranged from .15 to .23 at age $4, .24$ to .34 at age $5, .24$ to .37 at age 6 , and .28 to .42 at age 7 (see Table 4 ), very similar to those with the CAT/2 at age 8 that ranged from .21 to .30 at age $4, .21$ to .32 at age $5, .30$ to .43 at age 6 , and .36 to .50 at age 7 . 
The basic numeracy score of the EDI at age 6 was also moderately and similarly correlated with the computational skills at ages 8 and 10, with slightly higher correlations with the age 10 measure ( .32 for additions at $10 \mathrm{vs} .29$ at $8 ; .29$ for subtractions at $10 \mathrm{vs} .29$ at $8 ; .27$ for multiplications at $10 \mathrm{vs} .26$ at $8 ; .26$ for the divisions at 10 ; and .39 for the total score at 10 vs .35 at 8$)$.

Finally, correlations with teacher reports of school achievement indicated that computational skills at ages 8 and 10 were slightly stronger with concurrent measures of mathematics achievement (see Table 5) than with achievement in other domains (see Table 6) supporting the discriminant validity of the adapted version of the CAT/2 mathematics subtest. Indeed, concurrent associations with achievement in mathematics ranged between .29 and .45 at 10 and between .40 and .51 at 8 for computational skills subtests and total scores whereas concurrent correlations with achievement in other domains ranged from .26 to .43 at 10 and from .30 and .46 at 8 .

Longitudinal correlations were also stronger for achievement in mathematics (between .29 - .49) than for achievement in other domains (between .21-.49) for both age 8 and age 10 computational skills. Moreover, correlations of ages 8 and 10 computational skills with achievement scores were highly similar. Teacher-report achievement in mathematics correlations at age 7 ranged from $.30-.45$ at $10 \mathrm{vs} .38-.49$ at 8 ; from $.30-.44$ between mathematics achievement at 8 and computational skills at 10; from $.35-.47$ between mathematics achievement at 10 and computational skills at 8; and correlations at age 12 ranged from $.30-.40$ at 10 vs .29 - .41 at 8 (see Table 5). By contrast, longitudinal correlations with achievement in other domains at age 7 ranged from .29 -.49 at 10 vs .29-.46 at 8; between achievement in other domains at age 8 and age 10 computational skills ranged from $.28-.43$; between achievement at 
age 10 and computational skills at age 8 ranged from .25-.39 and with achievement in other domains at age 12 , ranged from $.21-.33$ at $10 \mathrm{vs} .22-.33$ at 8 (see Table 6 ). These results further support the discriminant validity of the adapted version of the CAT/2 mathematics subtest.

\section{Discussion}

The purpose of this study was to test the validity of an adapted mathematics subtest from the Canadian Achievement Test - Second Edition (CAT/2; Canadian Achievement Center, 1992) to assess computational skills in 10 year-olds. The results provide evidence of 1 ) the reliability of the measure with an internal consistency index superior to the original subtest at age 8,2 ) the cross-age convergent validity with the CAT/2 administered at age 8 , and 3) the cross-measure convergent and discriminant validity with standardized tests of number knowledge and basic numeracy as well as teacher reports of mathematic achievement and achievement in other school domains (reading, writing and science).

Reliability and validity evidence for this adapted instrument was limited to one concurrent measure done at age 10. However, based on the present findings, the results still showed that the adapted mathematics subtest of the Canadian Achievement Test could be used to reliably measure Quebec children's computational skills at age 10. The adapted age 10 version of the CAT/2 was validated on a large representative sample of children in Quebec and thus, supports the generalizability of the results to this population. Moreover, as the original measure developed for Canadian children was shown to reliably assess computational skills at age 8 in this sample, we also conclude that the adapted version could reliably assess Canadian children's computational skills at age 10 .

However, this instrument might be more useful for screening children with mathematical difficulties. The addition, the subtraction and the total score distributions of the computational 
skills at age 10 were negatively skewed, suggesting better psychometric proprieties to detect children with lower mathematic abilities in the simpler operations. Despite the inclusion of more difficult items, these asymmetric distributions might reflect a possible ceiling effect of the measure, and reduced efficiency to capture variance among children especially in addition and subtraction.

Finally, by covering a period from age 4 to grade 6 , the results provided additional support for the stability of mathematics performance throughout childhood. The computational skills at age 10 were more associated with measures tapping into mathematic performance than measures of achievement in other school domains; and the associations of the computational skills at ages 8 and 10 with the measures of number knowledge, basic numeracy and mathematics achievement from ages 4 to 12 were somewhat similar. These results parallel those of other studies showing high stability of achievement in mathematics (Garon-Carrier et al., 2014). From an individual perspective, this high stability of mathematic achievement over time points out how early mathematic experiences shapes later mathematic abilities. Indeed, one previous study from our group has shown early number knowledge to predict later individual variation in mathematic achievement, supporting the need to focus on early childhood as a crucial developmental window to learn numbers (Garon-Carrier et al., 2014).

However, many changes in numerical ability occur across development despite the high stability of mathematic achievement. For example, learning about fractions emerges as a crucial process in mathematic development. The acquisition of fractions lead children to understand that several apparently invariant properties of whole numbers such as having one single successor, constantly increasing with addition and multiplication, or invariably decreasing with subtraction and division, are erroneous and do not define numbers in general (Siegler, Thompson, \& 
Schneider, 2011). Accordingly, frequent and accurate assessment of children's mathematic abilities is needed throughout childhood and the adapted CAT2 computational skills at age 10 can be one tool used to carry those assessments beyond the first tier of primary school. Follow-up versions could be developed based on the principles highlighted here and their validity assessed within the same framework.

\section{References}

Canadian Achievement Test, Second Edition (1992). Canadian Test Center. Retrieved from http://www.canadiantestcentre.com/

Entwisle, D. R., \& Alexander, K. L. (1990). Beginning school math competence: Minority and majority comparisons. Child Development, 61, 454-471. doi: 10.2307/1131107

Garon-Carrier, G. Boivin, M., Dionne, G., Lemelin, J-P., Kovas, K., Séguin, J., Vitaro, F., \& Tremblay, R. E. (in preparation). Developmental trajectories of number knowledge and later mathematics and school achievement.

Gersten, R., Clarke, B. S., \& Jordan, N. C. (2007). Screening for mathematics difficulties in K-3 students. NH: RMC. Research Corporation, Center on Instruction. Retrieved from http://www.centeroninstruction.org/files/COI\%20Math\%20Screening1.pdf

Gersten, R., Jordan, N. C., \& Flojo, J. R. (2005). Early Identification and interventions for students with mathematics difficulties. Journal of Learning Disabilities, 38, 293-304. doi: $10.1177 / 00222194050380040301$

Graham, J. W., Olchowski, A. E., Gilreath, T. D. (2007). How many imputations are really needed? Some practical clarifications of multiple imputation theory. Prevention Science, 8, 206-213. doi: 10.1007/s11121-007-0070-9

Hecht, S. A., \& Vagi, K. J. (2010). Sources of group and individual differences in emerging 
fraction skills. Journal of Educational Psychology,102, 843-859. doi:10.1037/a0019824

James, C. \& Francis-Pelton, L. (2005). Using Achievement Test Scores to Predict Student Success in Adult Basic Education. The Canadian journal for the study of adult education, 19, 1-13.

Janus, M. \& Offord, D. (2007). Development and psychometric properties of the Early Development Instrument (EDI): A measure of children's school readiness. Canadian Journal of Behavioral Science, 39, 1-22. doi: 10.1037/cjbs2007001

Jordan, N., Glutting, J., \& Ramineni, C. (2010). The importance of number sense to mathematics achievement in first and third grade. Learning and Individual Differences, 20, 82-88. doi: 10.1016/j.lindif.2009.07.004

Ministère de l'Éducation, des Loisir et du Sports (MELS, 2013). Progression des apprentissages au primaire. Retrieved from http://www1.mels.gouv.qc.ca/progressionPrimaire/mathematique/index.asp?page=arithm etique_03

Muthén, L.K. and Muthén, B.O. (1998-2004). Mplus User's Guide. Third Edition. Los Angeles, CA: Muthén \& Muthén

National Council of Teachers of Mathematics (NCTM) (2006). Curriculum focal points for prekindergarten through grade 8 mathematics. Washington, DC: National Council of Teachers of Mathematics. <http://www.nctm.org/focalpoints/downloads.asp>.

OECD (2010), PISA 2009 Results: What Students Know and Can Do - Student Performance in Reading, Mathematics and Science (Volume I). Retrieved from http://dx.doi.org/10.1787/9789264091450-en

Okamoto, Y., \& Case, R. (1996). II. Exploring the microstructure of children's central 
conceptual structures in the domain of number. Monographs of the Society for Research in Child Development, 61, 27-58. doi: 10.1111/j.1540-5834.1996.tb00536.x

Peugh, J. L. \& Enders, C. K. (2004). Missing Data in Educational Research: A Review of Reporting Practices and Suggestions for Improvement. Review of Educational Research, 74, 525-556. doi: 10.3102/00346543074004525

Resnick, L. (1989). Developing mathematical knowledge. American Psychologist, 44, 162-169. doi: $10.1037 / 0003$

Reyna, V. F. \& Brainerd, C. J. (2007). The importance of mathematics in health and human judgment: Numeracy, risk communication, and medical decision making. Learning and Individual Differences, 17, 147-159. doi: 10.1016/j.lindif.2007.03.010

Siegler, R. S., Thompson, C. A., \& Schneider, M. (2011). An integrated theory of whole number and fractions development. Cognitive Psychology, 62, 273-296. doi:

10.1016/j.cogpsych.2011.03.001

SPSS Inc. (2011). SPSS Base 20.0 for Windows User's Guide. SPSS Inc., Chicago, IL. 
a. Additions

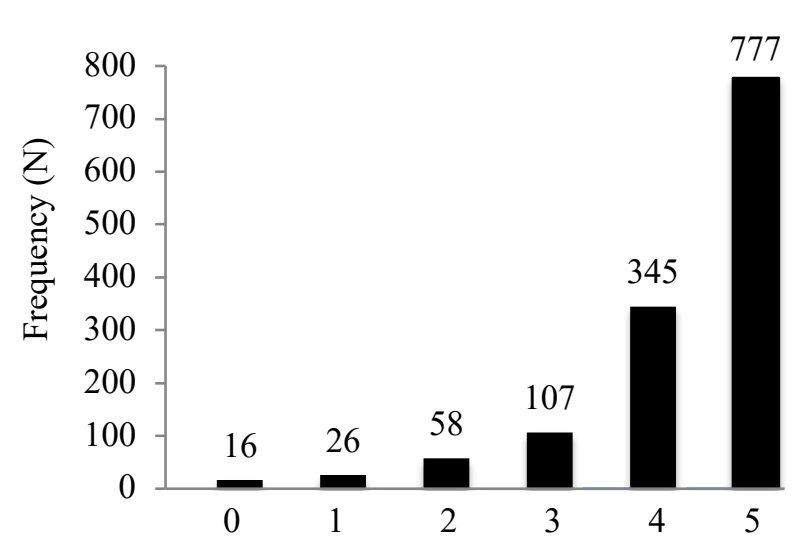

c. Multiplications

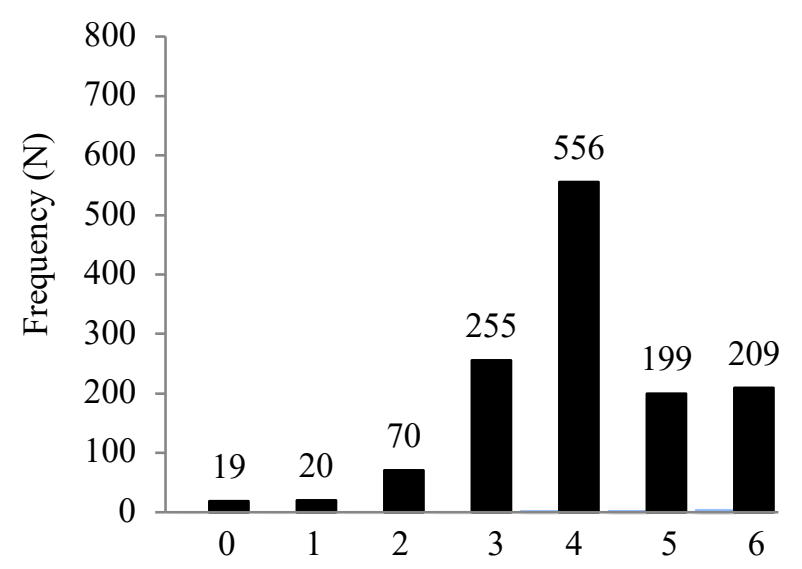

b. Subtractions

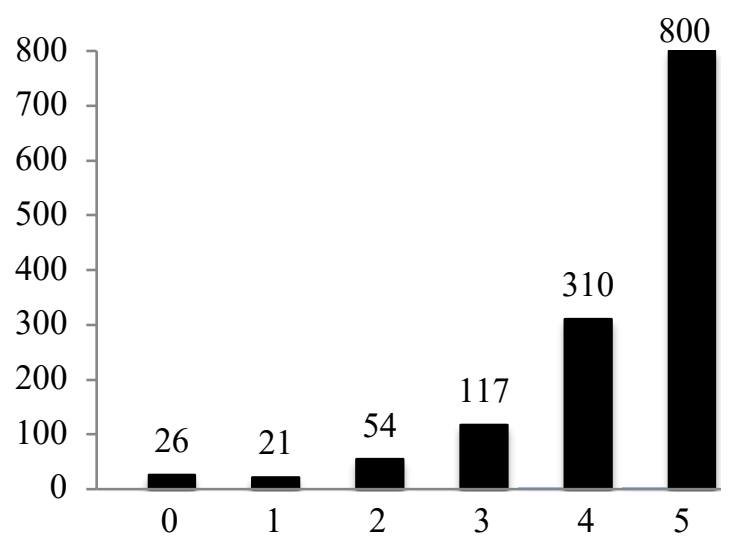

d. Divisions

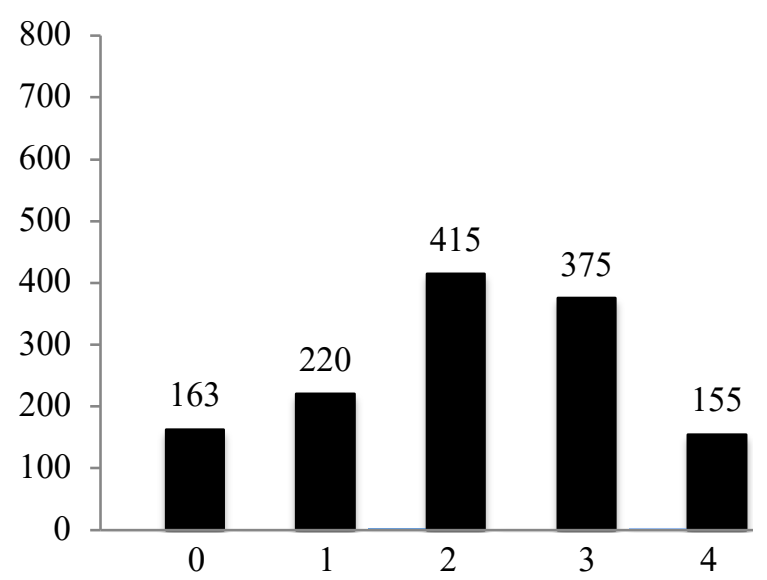

Figure 1. Number of children per number of succeeds items for each mathematics computational operations subtest. 
Table 1

Descriptive statistics for computational skills at age $8(C A T / 2)$ and the adapted version at age 10.

\begin{tabular}{lccccc}
\hline & $\mathrm{N}$ & $\mathrm{M}$ & $\mathrm{SD}$ & Min & Max \\
\hline Computational skills 8 years & & & & & \\
Total Score & 1466 & 13.13 & 4.71 & 0 & 21 \\
Addition & 1466 & 5.16 & 1.63 & 0 & 7 \\
Subtraction & 1466 & 5.30 & 2.28 & 0 & 8 \\
$\quad$ Multiplication & 1466 & 2.67 & 1.94 & 0 & 6 \\
Computational skills 10 years & & & & & \\
Total Score & 1328 & 14.79 & 3.42 & 0 & 20 \\
Addition & 1329 & 4.31 & 1.06 & 0 & 5 \\
Subtraction & 1328 & 4.31 & 1.10 & 0 & 5 \\
Multiplication & 1328 & 4.06 & 1.24 & 0 & 6 \\
Division & 1328 & 2.10 & 1.18 & 0 & 4 \\
\hline
\end{tabular}


Table 2

Descriptive statistics for the number knowledge (NKT), the total score of basic numeracy module (EDI), the school achievement in mathematics, science, reading, and writing.

\begin{tabular}{|c|c|c|c|c|c|}
\hline & $\mathrm{N}$ & $\mathrm{M}$ & SD & Min & Max \\
\hline \multicolumn{6}{|c|}{ Number knowledge } \\
\hline 4 years & 1768 & 5.60 & 3.92 & 0 & 18 \\
\hline 5 years & 989 & 9.61 & 4.10 & 1 & 18 \\
\hline 6 years & 1189 & 13.29 & 3.27 & 3 & 18 \\
\hline 7 years & 1426 & 13.17 & 2.60 & .67 & 18 \\
\hline \multicolumn{6}{|c|}{ Basic numeracy } \\
\hline 6 years & 965 & 8.99 & 1.90 & 0 & 11 \\
\hline \multicolumn{6}{|c|}{ Teacher ratings of achievement in mathematics } \\
\hline 7 years & 1269 & 3.67 & 1.17 & 1 & 5 \\
\hline 8 years & 1244 & 3.62 & 1.20 & 1 & 5 \\
\hline 10 years & 922 & 3.52 & 1.18 & 1 & 5 \\
\hline 12 years & 934 & 3.44 & 1.24 & 1 & 5 \\
\hline \multicolumn{6}{|c|}{ Teacher ratings of achievement in science } \\
\hline 10 years & 820 & 3.59 & .99 & 1 & 5 \\
\hline 12 years & 849 & 3.55 & 1.06 & 1 & 5 \\
\hline \multicolumn{6}{|c|}{ Teacher ratings of achievement in reading } \\
\hline 7 years & 1288 & 3.52 & 1.33 & 1 & 5 \\
\hline 8 years & 1259 & 3.54 & 1.28 & 1 & 5 \\
\hline 10 years & 951 & 3.42 & 1.26 & 1 & 5 \\
\hline 12 years & 979 & 3.37 & 1.23 & 1 & 5 \\
\hline \multicolumn{6}{|c|}{ Teacher ratings of achievement in writing } \\
\hline 7 years & 1282 & 3.40 & 1.29 & 1 & 5 \\
\hline 8 years & 1260 & 3.37 & 1.26 & 1 & 5 \\
\hline 10 years & 945 & 3.30 & 1.26 & 1 & 5 \\
\hline 12 years & 976 & 3.29 & 1.30 & 1 & 5 \\
\hline
\end{tabular}


Table 3

Correlations between the Computational skills at age 8 and 10

\begin{tabular}{llllllll}
1 & 2 & 3 & 4 & 5 & 6 & 7 & 8 \\
\hline
\end{tabular}

Computational skills 8 years

1. Total Score

2. Addition .79

3. Subtraction

$.86 \quad .60$

4. Multiplication

$\begin{array}{lll}.74 & .38 & .39\end{array}$

Computational skills 10 years

5. Total Score

$\begin{array}{llll}.47 & .42 & .44 & .25\end{array}$

6. Addition

$\begin{array}{lllll}.29 & .29 & .27 & .13 & .71\end{array}$

7. Subtraction

$\begin{array}{llllll}.35 & .34 & .34 & .15 & .72 & .51\end{array}$

8. Multiplication

$\begin{array}{lllll}.37 & .31 & .34 & .23 & .75\end{array}$

.33

$\begin{array}{llllll}.35 & .30 & .33 & .21 & .73 & .32\end{array}$
.34

9. Division

.35

$30 \quad .33$

Note. The results were controlled for age \& school grade. 
Table 4

Correlations between the Computational skills at age 10 and the number knowledge from age 4 to 7

\begin{tabular}{llllllllll}
\hline & 1 & 2 & 3 & 4 & 5 & 6 & 7 & 8 & 9 \\
\hline $\begin{array}{l}\text { Computational skills 8 years } \\
\text { 1. Total Score }\end{array}$ & & & & & & & & & \\
Computational skills 10 years & & & & & & & & \\
2. Total Score & .47 & & & & & & & \\
3. Addition & .29 & .71 & & & & & & \\
4. Subtraction & .35 & .72 & .51 & & & & & \\
5. Multiplication & .37 & .75 & .33 & .34 & & & & \\
6. Division & .35 & .73 & .32 & .30 & .46 & & & \\
Number knowledge & & & & & & & & \\
7. 4 years & $\mathbf{. 3 0}$ & $\mathbf{. 2 3}$ & $\mathbf{. 1 7}$ & $\mathbf{. 1 9}$ & $\mathbf{. 1 5}$ & $\mathbf{. 1 5}$ & & & \\
8. 5 years & $\mathbf{. 3 2}$ & $\mathbf{. 3 4}$ & $\mathbf{. 2 5}$ & $\mathbf{. 2 5}$ & $\mathbf{. 2 4}$ & $\mathbf{. 2 5}$ & .43 & & \\
9. 6 years & $\mathbf{. 4 3}$ & $\mathbf{. 3 7}$ & $\mathbf{. 2 8}$ & $\mathbf{. 3 2}$ & $\mathbf{. 2 5}$ & $\mathbf{. 2 4}$ & .36 & .55 & \\
10.7 years & $\mathbf{. 5 0}$ & $\mathbf{. 4 2}$ & $\mathbf{. 3 4}$ & $\mathbf{. 3 3}$ & $\mathbf{. 2 8}$ & $\mathbf{. 2 9}$ & .37 & .42 & .51 \\
\hline
\end{tabular}

Note. The results were controlled for age \& school grade. 
Table 5

Correlation between Computational skills at age 10 and math achievement from age 7 to 12

$\begin{array}{lllllllll}1 & 2 & 3 & 4 & 5 & 6 & 7 & 8 & 9\end{array}$

\section{Computational skills 8 years}

1. Total Score

Computational skills 10 years

2. Total Score .47

3. Addition

$.29 \quad .71$

4. Subtraction

$\begin{array}{lll}.35 & .72 & .51\end{array}$

5. Multiplication

$\begin{array}{llll}.37 & .75 & .33 & .34\end{array}$

6. Division

$\begin{array}{lllll}.35 & .73 & .32 & .30 & .46\end{array}$

Teacher ratings of achievement in mathematics

7. 7 years

$\begin{array}{llllll}.49 & .45 & .30 & .34 & .34 & .34\end{array}$

8. 8 years

$\begin{array}{llllll}.51 & .44 & .30 & .33 & .32 & .33\end{array}$

9. 10 years

$.47 \quad .45$

$.41 \quad .40$

$.29 \quad .33$

$.35 \quad .34$

10. 12 years

$\begin{array}{lll}40 \quad .24 & .32\end{array}$

.31

$.30 \quad .48$

.69

Note. The results were controlled for age $\&$ school grade. 
Table 6

Correlations between the Computational skills at age 10 and achievement in Science, Reading, and Writing from age 7 to 12

\begin{tabular}{|c|c|c|c|c|c|c|c|c|c|c|c|c|c|c|c|}
\hline & 1 & 2 & 3 & 4 & 5 & 6 & 7 & 8 & 9 & 10 & 11 & 12 & 13 & 14 & 15 \\
\hline \multicolumn{16}{|c|}{ Computational skills 8 years } \\
\hline \multicolumn{16}{|c|}{ 1. Total Score } \\
\hline \multicolumn{16}{|c|}{ Computational skills 10 years } \\
\hline 2. Total Score & .47 & & & & & & & & & & & & & & \\
\hline 3. Addition & .29 & .71 & & & & & & & & & & & & & \\
\hline 4. Subtraction & .35 & .72 & .51 & & & & & & & & & & & & \\
\hline 5. Multiplication & .37 & .75 & .33 & .34 & & & & & & & & & & & \\
\hline 6. Division & .35 & .73 & .32 & .30 & .46 & & & & & & & & & & \\
\hline \multicolumn{16}{|c|}{$\begin{array}{l}\text { Teacher ratings of } \\
\text { achievement in science }\end{array}$} \\
\hline 7. 10 years & .29 & .38 & .26 & .28 & .29 & .29 & & & & & & & & & \\
\hline 8. 12 years & .29 & .32 & .21 & .25 & .25 & .23 & .45 & & & & & & & & \\
\hline \multicolumn{16}{|c|}{$\begin{array}{l}\text { Teacher ratings of } \\
\text { achievement in reading }\end{array}$} \\
\hline 8. 7 years & .38 & .44 & .33 & .32 & .32 & .31 & .49 & .41 & & & & & & & \\
\hline 10. 8 years & .38 & .43 & .31 & .34 & .29 & .30 & .57 & .45 & .72 & & & & & & \\
\hline 11. 10 years & .32 & .40 & .28 & .30 & .31 & .30 & .68 & .52 & .60 & .66 & & & & & \\
\hline 12. 12 years & .29 & .33 & .24 & .27 & .24 & .22 & .73 & .66 & .51 & .57 & .64 & & & & \\
\hline \multicolumn{16}{|c|}{$\begin{array}{l}\text { Teacher ratings of } \\
\text { achievement in writing }\end{array}$} \\
\hline 13. 7 years & .36 & .44 & .35 & .32 & .33 & .29 & .51 & .41 & .88 & .72 & .62 & .53 & & & \\
\hline 14. 8 years & .36 & .42 & .32 & .33 & .30 & .28 & .54 & .44 & .69 & .85 & .64 & .58 & .71 & & \\
\hline 15. 10 years & .31 & .43 & .30 & .33 & .32 & .31 & .67 & .49 & .63 & .66 & .81 & .65 & .65 & .67 & \\
\hline 16. 12 years & .32 & .33 & .22 & .26 & .22 & .25 & .45 & .63 & .53 & .58 & .63 & .82 & .55 & .62 & .68 \\
\hline
\end{tabular}

Note. The results were controlled for age $\&$ school grade. 